\title{
Evaluation of Esophageal Motility Using Multichannel Intraluminal Impedance in Healthy Children and Children With Gastroesophageal Reflux
}

\author{
Maria Rita Di Pace, Anna Maria Caruso, Pieralba Catalano, \\ Alessandra Casuccio, and Enrico De Grazia
}

\begin{abstract}
Objective: Multichannel intraluminal impedance (MII) directly evaluates esophageal bolus transport. There is a good correlation between MII and manometry in healthy adults, but there are no reports concerning children. The aim of the present study was to determine normal values of esophageal motility using only impedance measurements in healthy children and in a pediatric population with gastroesophageal reflux (GER).

Patients and Methods: We described in the present study 60 children submitted to $\mathrm{pH}-\mathrm{MII}$ for 24 hours for suspected GER. Patients were divided into 2 different groups on the basis of their $\mathrm{pH}-\mathrm{MII}$ report. Group 1 patients showed acid GER, whereas group 2 patients had negative $\mathrm{pH}-\mathrm{MII}$ analysis for GER despite symptoms. We described impedance reflux and motility parameters on 10 standardized swallows: number of reflux, mean acid clearing time, median bolus clearing time, bolus presence time, total bolus transit time, segmental transit time, and total propagation velocity. Results: In group 1, the median mean acid clearing time was 151 seconds, whereas the median mean bolus clearing time was 25 seconds. In group 2 patients, all of the reflux parameters were normal. In group 1 the median bolus presence time at each measuring site, the median total bolus transit time, and the median segmental transit time were significantly greater and total propagation velocity lower than values reported in group $2(P<0.001)$, if compared with those described for adult patients.

Conclusions: The pH-MII is an ideal test in children because it studies GER with its characteristics and motility pattern. Our report summarizes for the first time impedance motility parameters in healthy children.
\end{abstract}

Key Words: esophageal motility, gastroesophageal reflux, multichannel intraluminal impedance

(JPGN 2011;52: 26-30)

$\mathrm{T}$ he main motor functions of the esophagus are to clear swallowed contents effectively into the stomach and prevent the reflux of gastric contents back into the esophagus. Esophageal manometry is considered the criterion standard for studying the esophageal motility, but it is only an indirect assessment. Actually, so far, esophageal motility studies have been performed using either

Received January 29, 2010; accepted May 10, 2010.

From the Pediatric Surgical Unit, Department of Mother and Child Care, University of Palermo, Palermo, Italy.

Address correspondence and reprint requests to Anna Maria Caruso, Division of Pediatric Surgery, University of Palermo, Via Alfonso Giordano 3, Palermo, Italy (e-mail: annacaruso2@libero.it).

The authors report no conflicts of interest.

Copyright $(1) 2010$ by European Society for Pediatric Gastroenterology, Hepatology, and Nutrition and North American Society for Pediatric Gastroenterology, Hepatology, and Nutrition

DOI: 10.1097/MPG.0b013e3181e72c24 radiology or scintigraphy, but the applicability of these techniques is limited, especially in children, because of the exposure to radiation. Multichannel intraluminal impedance (MII) is a new, nonradiation technique, which has been used to evaluate esophageal bolus transport and which can provide a functional outcome of the esophageal motor function. Validation studies have found an excellent correlation between MII and videofluoroscopy. There is also a good correlation between MII and manometry in healthy subjects and in patients with gastroesophageal reflux (GER) disease $(1-3)$.

GER is common in children: on the basis of literature review, $>80 \%$ of premature infants may present with some GER symptoms, whereas the prevalence of this condition decreases to $20 \%$ to $30 \%$ in infants and to $2 \%$ to $7 \%$ in older children (4-6). MII has been used as a diagnostic test for GER disease in children. The main advantage over traditional $\mathrm{pH}$ monitoring is its ability to detect both acid and nonacid GER and to differentiate between liquid and gas GER. With multiple impedance sensors, the MII technique routinely detects the proximal extent of a GER episode (7-11).

In patients with GER disease, failed peristalsis and hypotensive peristaltic sequences in the esophagus may be observed, and often the severity of peristaltic dysfunction is correlated with the prevalence of symptoms (12-14). Tutuian et al (15) described impedance motility parameters and reported normal values for impedance changes with liquid and viscous swallows, but there are no reports concerning healthy children and children with GER.

The aim of the present study was to determine normal values of esophageal motility based on impedance changes, using only impedance measurements in healthy children and in a pediatric population with GER.

\section{PATIENTS AND METHODS}

\section{Patients}

The present study was performed during a 1-year period between April 2008 and September 2009. Among all patients submitted to $\mathrm{pH}-\mathrm{MII}$ for 24 hours with motility analysis for suspected GER, we selected and described only 60 patients with a mean age of 7.5 years (range 5-10 years).

All of the patients complained of either typical or atypical "supraesophageal" GER symptoms. Five patients underwent, 2 years earlier, an isolated $\mathrm{pH}$ monitoring that was negative for GER. Patients were divided into 2 different groups on the basis of their $\mathrm{pH}-\mathrm{MII}$ report. There were no important differences regarding age and sex in 2 groups (group 1: mean age 7 years $\pm 1.5,16$ girls and 14 boys; group 2: mean age 8.3 years $\pm 1.5,17$ girls and 13 boys). We have based our evaluation of pathological GER on number and height of reflux, presence of $\mathrm{pH}$-only and re-reflux, and 
values of mean acid and bolus clearance time. Group 1 patients showed acid GER, whereas group 2 patients had negative $\mathrm{pH}-\mathrm{MII}$ analysis for GER despite symptoms. We considered the latter patients a control group of healthy subjects. To describe a homogeneous cohort of patients, we excluded from the study patients with nonacidic reflux. No patients had undergone surgical correction of congenital malformations or fundoplication for GER. None of the patients was taking medications known to influence esophageal motor function.

Parents were asked to sign an informed consent before the procedure. All of the children were admitted to our unit on the day of the procedure and discharged the following day.

\section{Procedure}

All of the patients underwent 24-hour combined esophageal pH-MII monitoring, using hardware and software by Sandhill Technologies (Sandhill Scientific,). The procedure was performed with age-appropriate probes with 6 impedance amplifiers $1.5-\mathrm{cm}$ apart, the first one placed just above the tip; the probe included a single esophageal $\mathrm{pH}$ recording channel positioned $2 \mathrm{~cm}$ above the tip. The correct placement of the probe was confirmed by fluoroscopy. Recording of the MII was performed with a Sleuth mobile impedance recorder. All of the patients were asked to observe some rules: stop antiacidic drugs at least 10 days before the procedure, do not drink or eat acidic foods, and eat and drink only during regular meals. Moreover, patients and parents were asked to record the exact time of every meal, sleeping and recumbent periods, and any possible GER symptom. The examination was validated only if the duration was at least 20 hours.

The following day, when the patients were calmer and collaborating, before removing the probe, we performed the motility analysis. In the supine position, children were given 10 swallows of 5-mL normal saline (standardized impedance value), each 20 to 30 seconds apart. BioView analysis software was used for automatic calculation of acid score. Considering the age of our patients, we used the DeMeester score for the evaluation of acid GER. The tracings were revised visually and manually for reflux and motility parameters.

\section{Impedance Analysis}

\section{Characteristic Pattern Produced by a Bolus Swallow}

The esophagus starts at a resting value (Fig. 1A) that represents the collapsed esophageal walls on the catheter. When a swallow is initiated, air is also swallowed. Air separates from the bolus and enters the measuring segment first, causing an increase in impedance (Fig. 1B). After the passage of air, the actual bolus causes a sharp decrease in impedance due to its conductivity and its effect on luminal dilatation. The bolus enters, traverses, and exits the measuring segments (Fig. $1 \mathrm{C}, \mathrm{D}$, and E, respectively). After the passage of the bolus, the lumen-occluding contraction (Fig. 1F) causes an increase in impedance. If the contraction wave completely clears the bolus from the segment, a return to the original impedance baseline is seen (Fig. 1G). If a return is not seen, one can assume that the bolus has not been successfully propagated through that segment (3).

We carefully describe only impedance motility parameters (15) that are the object of evaluation and discussion of the present study.

MII events (MIIe): decrease in impedance to $50 \%$ of the baseline value, in at least 2 consecutive recording channel with upward (reflux) or downward (swallow) direction. Acidic MIIe: associated $\mathrm{pH}$ drop $<4$. Nonacidic MIIe: associated $\mathrm{pH}$ value $>4$.

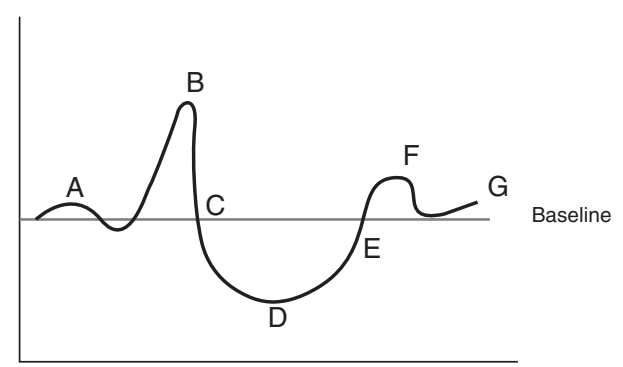

FIGURE 1. The esophagus starts at a resting value at baseline (A) that represents the collapsed esophageal walls on the catheter. When a swallow is initiated, air is also swallowed. Air enters in the first measuring segment causing an increase in impedance (B). After the passage of air, the bolus causes a decrease in impedance due to its conductivity and its effect on luminal dilatation $(\mathrm{C})$. The bolus enters, traverses, and exits the measuring segments $(C, D$, and $E$, respectively). After the passage of the bolus, the lumen-occluding contraction ( $F$ ) causes an increase in impedance. If the contraction wave completely clears the bolus from the segment, then a return to the original impedance baseline is seen (G).

Mean acid clearing time: mean time in seconds required for the $\mathrm{pH}$ to go back to 4.5 after an episode of acidic reflux. Median bolus clearing time: median time in seconds required for the impedance to go back to the initial threshold value after an episode of bolus reflux.

We have analyzed numbers of acidic reflux, isolated drops of $\mathrm{pH}$, superimposed reflux, and height of reflux; retrograde bolus movements that reached at least channel 2 in the upper esophagus were considered high refluxes.

Esophageal function was assessed by manual evaluation of these specific motility parameters. Bolus presence time (BPT): time elapsed between bolus entry and bolus exit at each impedancemeasuring site. Total bolus transit time (TBTT): time elapsed between bolus entry at the most proximal recording segment and bolus exit at the most distal recording segment. Segmental transit time (STT): time elapsed between bolus entry at given level above lower esophageal sphincter and bolus exit at the next lower level. Total propagation velocity (TPV): speed with which the bolus crosses all of the impedance channels.

Complete bolus transit for a swallow was defined as one for which BPT at all sites (BPT1-6), 5 measurements of STT (STT Ch $1-2$, Ch 2-3, Ch3-4, Ch4-5, Ch5-6), and 1 value of TBTT and TPV. Swallows were classified by MII as complete bolus transit, if bolus entry occurred at the most proximal site and bolus exit points were recorded in all distal impedance-measuring sites or incomplete bolus transit if bolus exit was not identified at any of the distal impedance-measuring sites.

\section{Statistical Analysis}

Data were collected and analyzed by SPSS version 14.0 (SPSS, Inc, Chicago, IL). All of the continuous data were expressed as a mean \pm standard deviation of the mean. Statistical analysis of quantitative data, including descriptive statistics, was performed for all the items. Frequency analysis was performed with the $\chi^{2}$ test. The 1-way analysis of variance and the Mann-Whitney $U$ statistic test were used for parametric and nonparametric analysis, respectively. All of the $P$ values were 2 -sided and $P$ values $<0.05$ were considered to indicate statistical significance. 


\section{RESULTS}

In the group of 30 patients with GER (group 1), an average of 40 episodes of acidic retrograde bolus movement was detected. By probe alone, an average of 8 episodes of $\mathrm{pH}<4$ were detected independently by MII. An average of 4 re-reflux was detected. Eighty percent of the reflux reached the proximal esophagus. The median mean acid clearing time was 151 seconds, whereas the median median bolus clearing time was 25 seconds. In all of the patients the symptom index was $>80 \%$.

In group 2 patients, all of the reflux parameters were normal, pointing out the absence of pathological reflux, both acid and nonacidic, and the absence of correlation between symptoms and reflux. These results are summarized in Table 1 .

As far as specific analysis of esophageal motility performed through the swallowing test is concerned, the obtained results were statistically significant in both groups and are shown in Table 2. Normal values for children have not been established and therefore these results have been compared with those described for adult patients.

All 10 swallows studied were complete bolus transits in both groups. The BPT progressively increased in each segment as the bolus traveled down the esophagus. In patients with acidic reflux the median BPT at each measuring site was significantly longer $(P<0.001)$ than values reported in patients without reflux (BPT1: 5.0 vs 1.8 seconds; BPT2: 5.4 vs 2.1 seconds; BPT3: 5.9 vs 2.6 seconds; BPT4: 6.5 vs 3.3 seconds; BPT5: 7.3 vs 4.5 seconds; BPT6: 8.5 vs 5.7 seconds). The median TBTT was significantly shorter $(P<0.001)$ in patients without reflux if compared with children with acid reflux ( 6.9 vs 8.8 seconds). The median STT between each measuring site was significantly shorter $(P<0.001)$ in control patients without reflux than in patients with acid reflux (STT1: 0.5 vs 2.3 seconds; STT2: 0.7 vs 2.4 seconds; STT3: 0.8 vs 2.5 seconds; STT4: 1.1 vs 2.7 seconds; STT5: 1.4 vs 3.0 seconds). The TPV was significantly slower $(P<0.001)$ in patients with reflux than in patients without reflux (1.7 vs $2.9 \mathrm{~cm} / \mathrm{second})$.

Analyzing the relation between BPT, TBTT, and STT, it is emphasized that responses with BPT values more prolonged at all sites always led to prolonged STT and TBTT.

Analyzing the results of the single patients with GER we have emphasized that there is a correlation between the presence of symptoms and esophageal dismotility: patients with longer values of TBTT, STT, and BPT, to parity of degree of reflux, bring more symptoms.

\section{DISCUSSION}

Peristaltic dysfunction of the esophagus is well documented in adults with GERD. Several studies demonstrated the association between reflux esophagitis and esophageal motor abnormalities. It is well known that patients with reflux esophagitis show reduced lower esophageal sphincter pressures, increased incidence of failed peristalsis, and reduced peristaltic amplitudes. Manometric studies defined these motor abnormalities as ineffective esophageal motor (IEM): sum total of the number of low-amplitude $(<30 \mathrm{mmHg})$ and nontrasmitted contractions in the distal esophagus being $30 \%$ or more of wet swallow. IEM is associated with an increased acid clearance time and therefore more severe mucosal damage. It is unclear whether GER leads to the development of IEM by repeated distal esophageal acid exposures or the presence of preexisting poor esophageal peristalsis leads to ineffective esophageal clearance mechanism, producing GER (16-22). Despite sporadic reports of occasional surgical or medical treatment of GER leading to improvement in peristalsis, most studies indicate that no changes in peristaltic amplitude occur after effective acid suppression and reflux control (23). In children, although motility patterns in GERD have been described (24), their interpretation is difficult because normative data do not exist.

MII is being used increasingly to study esophageal pathophysiology, and recently it has been used as a diagnostic test for GER disease. The main advantage over traditional pH-metry is its ability to detect both acid and nonacid GER, to identify both liquid and gas reflux, and to establish the height of reflux in the esophagus. The intraluminal electrical impedance is inversely proportional to the electrical conductivity of the luminal contents and the cross-sectional area. If a highly conductive bolus arrives at the measuring segment, then the impedance will decrease, whereas a luminal narrowing (contraction wave) causes an impedance increase. Hence, MII allows the evaluation of esophageal motility, as well as the assessment of bolus transport throughout the entire esophagus in real time without the use of radiation. For this reason the MII has been used in adults to evaluate the esophageal function directly. Manometry gives information about esophageal pressure pattern and sphincter function, but does not inform us about the bolus transit. MII not only detects the presence of esophageal flow but it also evaluates the direction of bolus transit, the duration of bolus presence, the time of acid, and bolus clearance.

In adults, the combination of MII and manometry has become a widely used technique and has been useful in studying the pathophysiology of motility disorders. The first studies and greatest part of those reported by literature are combined MII and manometry studies $(25,26)$. The evaluation of esophageal motility using only MII is successfully supported by comparative studies with manometry and fluoroscopy. The contraction wave seen on impedance is correlated with the maximal pressure produced during simultaneous manometry, and the bolus entry, transit, and exit with

TABLE 1. Impedance reflux parameter

\begin{tabular}{lcccccc}
\hline & \multicolumn{2}{c}{ Group 1(GER + ) } & & \multicolumn{2}{c}{ Group 2 (GER-) } & \\
\cline { 2 - 3 } Parameters & Mean $( \pm$ SD) & Range & & Mean $( \pm$ SD) & Range & $P$ \\
\hline No. reflux & $40.8(16.7)$ & $20-75$ & & $2.1(3.4)$ & $0-11$ & $<0.005$ \\
No. high reflux & $34.5(17.5)$ & $12-72$ & & $0.5(1.2)$ & $0-4$ & $<0.005$ \\
No. pH only & $8.0(3.2)$ & $2-15$ & & $0.4(0.6)$ & $0-2$ & $<0.005$ \\
No. re-reflux & $4.0(2.0)$ & $0-8$ & & $0.2(0.4)$ & $0-1$ & $<0.005$ \\
No. GER correlated symptoms & $32.1(16.1)$ & $13-72$ & & $0.1(0.2)$ & $0-1$ & $<0.005$ \\
MACT, s & $150.1(39.5)$ & $89-212$ & & $76.8(20.3)$ & $35-105$ & $<0.005$ \\
MBCT, s & $25.6(6.7)$ & $16-36$ & & $10.9(3.8)$ & $5-20$ & $<0.005$ \\
\hline
\end{tabular}

$\mathrm{MACT}=$ mean acid clearing time; $\mathrm{MBCT}=$ median bolus clearing time; $\mathrm{GER}=$ gastroesophageal reflux. 


\begin{tabular}{|c|c|c|c|c|c|}
\hline Total bolus transit time, $\mathrm{s}$ & $8.8(1.8)$ & $2.4-10.1$ & $6.9(0.7)$ & $6.1-8.3$ & $<0.005$ \\
\hline \multicolumn{6}{|l|}{ Bolus presence time, $\mathrm{s}$} \\
\hline At Z 1 & $5.0(1.1)$ & $2.6-6.3$ & $1.8(0.6)$ & $1.3-3.0$ & $<0.005$ \\
\hline At Z 3 & $5.9(1.1)$ & $3.1-7.1$ & $2.6(0.5)$ & $1.9-3.4$ & $<0.005$ \\
\hline At Z 4 & $6.5(1.4)$ & $2.3-7.7$ & $3.3(0.5)$ & $2.4-4.0$ & $<0.005$ \\
\hline At Z 5 & $7.3(1.5)$ & $2.4-8.7$ & $4.5(0.5)$ & $3.7-5.2$ & $<0.005$ \\
\hline At Z 6 & $8.5(0.6)$ & $7.4-9.6$ & $5.7(0.6)$ & $4.7-6.6$ & $<0.005$ \\
\hline \multicolumn{6}{|l|}{ Segment transit time, $s$} \\
\hline STT1 Z1-Z2 & $2.3(0.1)$ & $2.0-2.4$ & $0.6(0.1)$ & $0.4-0.7$ & $<0.005$ \\
\hline Total propagation velocity, $\mathrm{cm} / \mathrm{s}$ & $1.7(0.4)$ & $1.2-2.7$ & $3(0.2)$ & $2.8-3.4$ & $<0.005$ \\
\hline
\end{tabular}

$\mathrm{GER}=$ gastroesophageal reflux; STT $=$ segment transit time.

respect to the measuring segment have been correlated with simultaneous barium swallow $(15,27-29)$.

Few studies are reported in children, mainly because performing a study with both techniques implies the use of 2 catheters, and this is unacceptable in the pediatric population. Catheters have been therefore developed combining both techniques and also incorporating a feeding tube with no increase in size. However, this catheter does not allow the evaluation of $\mathrm{pH}$, which is extremely important in the pediatric age group.

Scintigraphic, $\mathrm{pH}$-metric, and manometric studies have demonstrated that esophageal acid clearance consists of 2 processes: first, rapid removal of most of intraluminal refluxate, achieved by gravity and primary or secondary peristalsis (volume clearance), and second, a slow neutralization of the acidified mucosa by swallowed saliva (chemical clearance). However, these studies could not determine whether in GERD the abnormality was due to impaired volume clearance, insufficient acid neutralization, or both. The $\mathrm{pH}-\mathrm{MII}$ is a nonradiological tool for studying esophageal volume and chemical clearance after reflux, and this is possible because it allows the appraisal of both $\mathrm{pH}$ and bolus transit.

Our report summarizes for the first time impedance parameters of esophageal motility in healthy children and children with GER using only $\mathrm{pH}-\mathrm{MII}$. In the pediatric age group, for ethical reasons, we cannot study a control group of healthy people. Hence, in our series the control group consists of children who underwent $\mathrm{pH}-\mathrm{MII}$ for GER symptoms, but had negative $\mathrm{pH}-\mathrm{MII}$ analysis. Normal values for children have not been established and so these results have been compared with those described for adults.

Lacking pediatric parameters of reference, we decided to evaluate and describe in this first study only patients older than 5 years and to exclude patients with nonacidic reflux and congenital malformation of esophagus to make the subset of patients more homogeneous. We do not know whether the type of reflux (acid or nonacid) influences the esophageal motility (30); patients with esophageal atresia have an important motor dysfunction and so we would not have had values of pediatric normal esophageal motility.

We described in group 1 only selected patients with a homogeneous pattern of acid GER; these patients reported an elevated number of acid GER and a high value of symptom index
(>80\%). Children with acid GER were compared with patients without GER (group 2), in which the pH-MII report has been particularly poor for reflux alterations, and no correlation between symptoms and GER has been found. The necessity to describe only selected groups has influenced the small number of patients reported in the present study.

In our study we carefully analyzed impedance motility parameters; in the $\mathrm{pH}$ report we have not reported the total DeMeester score value. We have described only some parameters, such as the number and height of reflux, the presence of $\mathrm{pH}$-only and re-reflux, and mean values of acid and bolus clearance time: these values, when pathological (group 1), correlate with prolonged motility parameters. We compared patients with and without GER to evaluate differences in motility parameters. In the group with acid GER (group 1) we have not correlated altered motility parameters with different values of pathological acid score. This is one of the limitations of our study.

Our findings concerning esophageal bolus transit by using MII are similar to those obtained by Tutuian et al (15) that are considered normal for healthy adults. In both groups all swallows are complete bolus transit; in fact, also in patients with GER, the altered esophageal motility is not serious enough to determine incomplete swallows. The presence of altered bolus transit is typical of patients with esophageal atresia in which the impedance analysis indicates incomplete exit of the wave impedance in distal sites.

All of the studied patients have no history of congenital malformations such as esophageal atresia or diaphragmatic hernia, and, for this reason, we assume that the esophageal motility of these patients is normal in the absence of specific symptoms or other esophageal abnormalities.

The presence of described motility abnormalities in GERD could explain the differences of bolus transit emphasized in our study between the 2 groups that, however, show values within the normal range for the adults. The main limitation of the present study was that it analyzes only liquid swallows. Previous reports have clearly shown that proposed normal values for MII parameters for liquid and viscous swallow are similar (15). Liquid and viscous boluses can have different transit patterns, and therefore additional clinical studies using both testing materials should be conducted. 
Impaired peristalsis is a major reason for the prolongation of esophageal acid exposure in reflux disease; evaluation of both GER and esophageal function to establish the type of more suitable treatment is therefore mandatory.

The pH-MII is an ideal test in children because it studies GER with its characteristics and motility pattern; it can be considered useful as a preoperative assessment in patients in whom antireflux surgery in considered. It also allows the correlation of symptoms with GER and esophageal dismotility. It is likely that in the future, patients will be selected for surgery on the basis of esophageal function test findings $(31,32)$.

In conclusion, our report summarizes for the first time impedance motility parameters in healthy children. These normal values can be used as reference values in the evaluation of patients with congenital esophageal malformation to establish the severity of esophageal dismotility. However, for a better explanation of the role of these preliminary data, additional studies of large series and the correlation of esophageal dismotility with endoscopic esophagitis (33) or with the outcome of esophageal surgery could be useful.

\section{REFERENCES}

1. Frieling $T$, Hermann $S$, Kuhlbusch $R$, et al. Comparison between intraluminal multiple electric impedance measurement and manometry in human esophagus. Neurogastroenterol Motil 1996;8:45-50.

2. Sifrim M, Sinly J, Holloway R, et al. Relevance of ineffective esophageal motility during esophageal acid clearence. Gut 2003;52:784-90.

3. Shay S, Tutuian R, Sifrim D, et al. Twenty-four hour ambulatory simultaneous impedance and $\mathrm{pH}$ monitoring: a multicenter report of normal values from 60 healthy volunteers. Am J Gastroenterol 2004;99: 1037-43.

4. Poets CF. Gastroesophageal reflux: a critical review of its role in preterm infants. Pediatrics 2004;113:128-32.

5. Gold BD. Outcome of pediatric gastroesophageal reflux disease: in the first year of life, in childhood and in adults. J Pediatr Gastroenterol Nutr 2003;37:S33-9.

6. Kim J, Keninger DL, Becker S, et al. Simultaneous development of pediatric GERD Caregiver Impact Questionnaire (PGCIQ) in American English and American Spanish. Health Qual Life Outcomes 2005;14:3:5.

7. Mattioli G, Pini-Prato A, Gentilini V, et al. Esophageal impedance/pH monitoring in pediatric patients: preliminary experience with 50 cases. Dig Dis Sci 2006;51:2341-7.

8. Van Wijk MP, Benninga MA, Omari T. Role of the multichannel intraluminal impedance technique in infants and children. $J$ Pediatr Gastroenterol Nutr 2008;48:2-12.

9. Rosen R, Nurko S. The importance of multichannel intraluminal impedance in the evaluation of children with persistent respiratory symptoms. Am J Gastronterol 2004;99:2452-8.

10. Woodley F, Mousa H. Acid gastroesophageal reflux reports in infants: a comparison of esophageal $\mathrm{pH}$ monitoring and multichannel intraluminal impedance measurements. Dig Dis Sci 2006;51:1910-6.

11. Condino A, Sondheimer J, Pan Z, et al. Evaluation of gastroesophageal reflux in pediatric patients with asthma using impedance $\mathrm{pH}$ monitoring. J Pediatr 2006;149:216-9.

12. Kahrilas PJ, Dodds WJ, Hogan WJ, et al. Esophageal peristaltic dysfunction in peptic esophagitis. Gastroenterology 1986;91:897-904.
13. Gill C, Bowes KL, Murphy PD, et al. Esophageal motor abnormalities in gastroesophageal reflux and the effects of fundoplication. Gastroenterology 1986;91:364-9.

14. Jacob P, Kahrilas PJ, Vanagunas et al. Peristaltic dysfunction associated with non obstructive dysphagia in reflux disease. Dig Dis Sci 1990; 35:939-42.

15. Tutuian R, Vela MF, Balaji NS, et al. Esophageal function testing with combined multichannel intraluminal impedance and manometry: multicenter study in healthy volunteers. Clin Gastroentrol Hepato 2003;1: 174-82.

16. Dantas RO, Aprile LRO. Esophageal striated muscle contractions in patients with gastroesophageal reflux symptoms. Dig Dis Sci 2002;47: 2586-90.

17. Simren M, Silny J, Holloway R, et al. Relevance of ineffective esophageal motility during esophageal acid clearance. Gut 2003;52:784-90.

18. Diener U, Patti MG, Molena D, et al. Esophageal dismotility and gastroesophageal reflux disease. J Gastrointest Surg 2001;5:260-5.

19. Leite LP, Johnston BT, Barrett J, et al. Ineffective esophageal motility (IEM). The primary finding in patients with nonspecific esophageal motility disorder. Dig Dis Sci 1997;42:1859-65.

20. Kim KY, Kim GH, Kim DU, et al. Is ineffective esophageal motility associated with gastropharyngeal reflux disease? World J Gastroenterol 2008;21:6030-5.

21. Ozin Y, Dagli U, Kuran S, et al. Manometric findings in patients with isolated distal gastroesophageal reflux. World J Gastroenterol 2009;21: 5461-4.

22. Kahrilas PJ, Pandolfino JE. Ineffective esophageal motility does not equal to GERD. Am J Gastroenterol 2003;98:715-7.

23. Wlliams D, Thompson DG, et al. Esophageal clearance function following treatment of esophagitis. Gastroenterology 1994;106:108-16.

24. Cucchiara S, Staiano A, Di Lorenzo C, et al. Esophageal motor abnormalities in children with gastroesophageal reflux and peptic esophagitis. J Pediatr 1986;108:907-10.

25. Savarino E, Tutuian R. Combined multichannel intraluminal impedance and manometry testing. Dig Liver Dis 2008;40:167-73.

26. Ngujen NQ, Rigda R, Conchillo J. Assessment of esophageal motor function using combined perfusion manometry and multi-channel intraluminal impedance measurement in normal subject. Neurogastroenterol Motil 2005;17:458-65.

27. Ngujen HN, Silny J. Multiple intraluminal electrical impedenzometry for recording of upper gastrointestinal motility: current results and further implications. Am J Gastroenterol 1999;94:306-17.

28. Silny J. Intraluminal multiple electric impedance procedure for measurement of gastrointestinal motility. J Gastrointest Motil 1991;3:151-62.

29. Silny J, Knigge KP, Fass J, et al. Verification of the intraluminal multiple electrical impedance measurements for the recording of gastrointestinal motility. Neurogastroenterol Motil 1993;5:107-22.

30. Wang VS, Feldman N, Maurer R. Esophageal motility in nonacid reflux compared with acid reflux. Dig Dis Sci 2009;54:1926-32.

31. Del Genio G, Tolone S, Del Genio F, et al. Prospective assessment of patient selection for antireflux surgery by combined multichannel intraluminal impedance pH monitoring. J Gastrointest Surg 2008;12: 1491-6.

32. Del Genio G, Tolone S, Del Genio F. Total fundoplication controls acid and non acid reflux: evaluation by pre and postoperative $24 \mathrm{~h} \mathrm{pH}-$ multichannel intraluminal impedance. Surg Endosc 2008;22:2518-23.

33. Somani SK, Ghoshal UC, Saraswat VA, et al. Correlation of esophageal $\mathrm{pH}$ and motor abnormalities with endoscopic severity of reflux esophagitis. Dis Esophagus 2004;17:58-62. 